\title{
Wellbore-reservoir Coupling Simulation of Geochemical Reactions Involving Carbon Dioxide
}

\author{
Yan $\mathrm{Shi}^{1 *}$, Xianchuang Huang ${ }^{1}$, Guanhong Feng ${ }^{2}$ \\ ${ }^{1}$ School of Municipal and Environmental Engineering, Jilin Jianzhu University, Changchun 130118, China \\ ${ }^{2}$ School of New Energy and Environment, Jilin University, Changchun130000, China
}

Corresponding Author Email: shiyan0311@163.com

https://doi.org/10.18280/ijht.370318

Received: 17 February 2019

Accepted: 8 June 2019

\section{Keywords:}

Wellbore-reservoir coupling simulation, geochemical reaction, carbon dioxide $\left(\mathrm{CO}_{2}\right)$, drift-flux model

\begin{abstract}
The existing simulation software for geochemical reactions involving carbon dioxide $\left(\mathrm{CO}_{2}\right)$ mostly focus on the reservoir, failing to take account of the wellbore. Considering the importance of temperature in geochemical reactions, this paper develops a wellbore-reservoir coupling geochemical simulation software for non-isothermal multiphase fluid. Based on TOUGHREACT v2.0, the software was programmed in Fortran in the light of the integrated wellbore-reservoir simulator T2Well, the conservation of momentum equation for onedimensional (1D) fluid, and the drift-flux model. Targeting a $\mathrm{CO}_{2}$ plume geothermal (CPG) project in the Songliao Basin, the author compared the wellbore-reservoir coupling model and the simple reservoir model in terms of water and heat transfer, mineral dissolution and precipitation, change in pore permeability, etc. The comparison shows that $\mathrm{CO}_{2}$ in the wellbore varies greatly in temperature and pressure; the injection well is much hotter at the bottom than at the wellhead. In the region near the injection well, the two models differed slightly despite the huge temperature difference; In the region near the production well, the wellbore-reservoir coupling model predicted slightly more violent dissolution and precipitation reactions and a greater CCS amount than the other model. The research findings lay the basis for the simulation of $\mathrm{CO}_{2}$ geological engineering.
\end{abstract}

\section{INTRODUCTION}

Carbon dioxide $\left(\mathrm{CO}_{2}\right)$ capture and storage $(\mathrm{CCS})$ is a technology aimed at reducing greenhouse gas (GHG) emissions [1]. To reduce the CCS cost, the $\mathrm{CO}_{2}$ capture, utilization and storage (CCUS) techniques were developed to utilize the $\mathrm{CO}_{2}$ before the CCS [2-4], namely, $\mathrm{CO}_{2}$-enhanced geothermal system $\left(\mathrm{CO}_{2}\right.$-EGS), $\mathrm{CO}_{2}$-enhanced coal bed methane $\left(\mathrm{CO}_{2}\right.$-ECBM $)$ recovery, $\mathrm{CO}_{2}$-enhanced water recovery $\left(\mathrm{CO}_{2}\right.$-EWR $)$ and $\mathrm{CO}_{2}$-enhanced oil recovery $\left(\mathrm{CO}_{2-}\right.$ EOR).

The $\mathrm{CO}_{2}$-EGS was proposed by Brown in 2000 [5]. Atrens et al. predicted that the CO2-EGS would be less effective at energy extraction than a water-EGS for conditions used in past EGS trials [6]. One year later, Randolph and Saar shifted the focus from fractured medium to porous medium, and put forward the $\mathrm{CO}_{2}$ plume geothermal (CPG) technology, which uses $\mathrm{CO}_{2}$ to recover geothermal energy from sedimentary basins [7]. For CPG, many scholars studied its heat extracting efficiency, such as Luo et al. [8] and $\mathrm{Xu}$ et al. [9]. There are also some studies on the non- isothermal flow in $\mathrm{CO}_{2}$ sequestration engineering such as Ruan et al. [10] and Singh et al. [11], their research focus wellbore and reservoir respectively. However, no studies mentioned above considered the reactive transport process and geochemical reaction.

During the CPG operation, the $\mathrm{CO}_{2}$ injection causes the surrounding rocks to dissolve or precipitate. As a result, the geothermal reservoir will face changes in porosity, permeability and mineral composition, and thus variation in its original flow field. Then, the reservoir and the original formation water will form a water-rock-gas system, kicking off a series of complex geochemical reactions. The minerals will dissolve and precipitation in the reactions, changing the physical properties (e.g. porosity and permeability of the reservoir) [12-13]

Temperature is the key to geothermal reactions. It directly bears on the fluidity of the fluid and the geochemical reaction rate of minerals. In geochemical simulations, the temperature of the injected $\mathrm{CO}_{2}$ fluid is generally handled in two approaches. Some software assume that the injected $\mathrm{CO}_{2}$ fluid and the reservoir have the same temperature, ignoring the thermal change of reactions [14]. Some treat the temperature of the $\mathrm{CO}_{2}$ fluid on the surface as the that entering the reservoir, taking account of the thermal change of reactions [15]. However, neither of the two simulation approaches can accurately describe the temperature of the $\mathrm{CO}_{2}$ fluid entering the reservoir.

Most of the existing geochemical simulation software only focus on the reservoir, failing to consider the wellbore. In actual physical process, the wellbore, as the passage between the surface and the underground, is indispensable for all geological engineering operations. After being injected at the wellhead, the low-temperature $\mathrm{CO}_{2}$ continuously picks up heat as it flows down along the wellbore, due to the heat transfer from the surrounding rocks and the conversion of gravitational potential energy [16]. The amount of temperature rise cannot be measured without calculation. Hence, the neglection of wellbore is bound to bring prediction errors. Considering the impacts of the wellbore on geochemical reactions, the wellbore and the reservoir should be treated as a whole in geochemical simulation models. 
This paper develops a wellbore-reservoir coupling geochemical simulation software for non-isothermal multiphase fluid that can accurately predict the geochemical reactions in geological engineering. Based on TOUGHREACT v2.0 [17], the software was programmed in Fortran in the light of the integrated wellbore-reservoir simulator T2Well-ECO2N [18], the conservation of momentum equation for one-dimensional (1D) fluid, and the drift-flux model [19]. Pan et al. has studied the mixture flow of $\mathrm{CO}_{2}$ and water along wellbore [20-21]. ECO2N is an EoS module developed for $\mathrm{CO}_{2}$ disposal in saline aquifer. It can deal with the phase balance of $\mathrm{CO}_{2}$ and water [22].

\section{PORGRAM DEVELOPMENT}

This paper attempts to develop a wellbore-reservoir coupling geochemical simulation software for non-isothermal multiphase multi-component fluid that can accurately simulate the geothermal reactions in the presence of $\mathrm{CO}_{2}$ and effectively solve geological and environmental problems involving one or more of the following fields: hydraulic field $(\mathrm{H})$, temperature field $(\mathrm{T})$ and chemical field $(\mathrm{C})$.

Based on the architecture of TOUGHREACT v2.0, the wellbore-reservoir coupling module was developed. The wellbore and the reservoir were treated as two separate subareas, and their multiphase flows were illustrated with different control equations. For the wellbore, the control equation is the Darcy's law for multiphase flow. For the reservoir, the control equation is the conservation of momentum equation for 1D fluid.

Since the conservation of momentum for multiphase flow is difficult to solve, the mixing velocity of the multiphase fluid was selected as the main variable for iteration. The drift-flux model was employed to process the mixing velocity, the drift velocity and the velocity of each phase. A unified Jacobian matrix was established for the two subareas and solved to couple the different fields. The $\mathrm{H}$ and $\mathrm{T}$ were fully coupled, while the $\mathrm{C}$ was partially coupled. The control equations are listed in the following table.

Table 1. The control equations of the simulation program

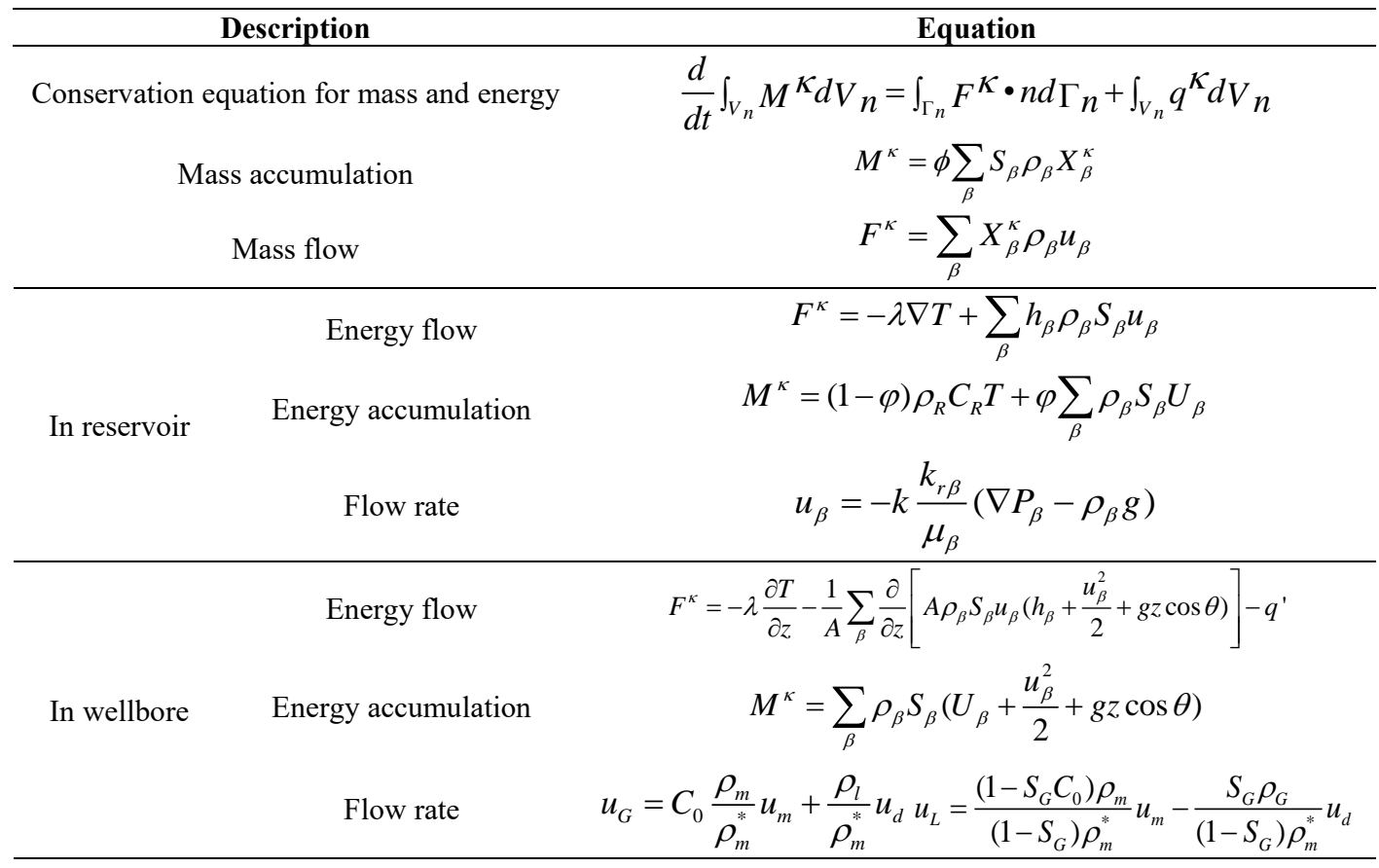

\section{MODEL CONSTRUCTION}

The developed program was applied to the geochemical simulation of deep plume geothermal energy. The simulation results were compared with those of TOUGHREACT v2.0, aiming to verify whether wellbore-reservoir coupling simulation is necessary and superior to simple reservoir simulation. The parameters of our model were extracted from $\mathrm{Xu}$ 's research [12]. The research data were measured from the Songliao Basin, northeastern China. $\mathrm{CO}_{2}$ was used to recovery deep geothermal energy and subjected to the CCS.

\subsection{Conceptual model}

Our simulation uses a three-dimensional 3D five-point model. As shown in Figure 1, the simulation site is $1,200 \mathrm{~m}$ wide, and the reservoir is $50 \mathrm{~m}$ in thickness. Considering its

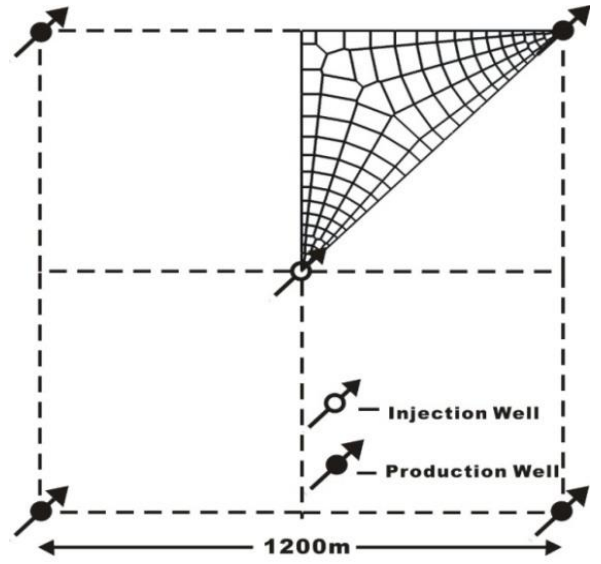

Figure 1. Sketch map of the five-point model (upper right: the $1 / 8$ simulated area) 
symmetry, only $1 / 8$ of the entire site was simulated. The simulated area was meshed nonuniformly. The meshed grids are denser in the near-well region.

The physical parameters of the reservoir were mostly cited from Xu's research (2014) (Table 2). In the wellbore-reservoir coupling model, the wellbore diameter was set to $0.2 \mathrm{~m}$. The specific parameters are given in Table 2. The heat transfer between the wellbore and the surrounding rocks was interpreted by a semi-analytical solution.

Table 2. Conceptual model and physical parameters

\begin{tabular}{|c|c|}
\hline \multicolumn{2}{|c|}{ Parameters of reservoir } \\
\hline Depth & $3800 \mathrm{~m}$ \\
\hline Thickness & $5 \mathrm{~m}$ \\
\hline Porosity & 0.1 \\
\hline Permeability & $1.0 \times 10^{-13} \mathrm{~m}^{2}$ \\
\hline Rock density & $2650 \mathrm{~kg} / \mathrm{m}^{3}$ \\
\hline Specific heat & $920 \mathrm{~J} / \mathrm{kg} /{ }^{\circ} \mathrm{C}$ \\
\hline Heat conductivity & $2.51 \mathrm{~W} / \mathrm{m} /{ }^{\circ} \mathrm{C}$ \\
\hline Area of whole domain & $1.44 \mathrm{~km}^{2}$ \\
\hline Well distance & $848.5 \mathrm{~m}$ \\
\hline \multicolumn{2}{|c|}{ Parameters of wellbore } \\
\hline Diameter & $0.2 \mathrm{~m}$ \\
\hline Friction coefficients & $2.4 \times 10^{-5} \mathrm{~m}$ \\
\hline Specific heat & $1000 \mathrm{~J} / \mathrm{kg} /{ }^{\circ} \mathrm{C}$ \\
\hline Heat conductivity & $2.51 \mathrm{~W} / \mathrm{m} /{ }^{\circ} \mathrm{C}$ \\
\hline
\end{tabular}

\subsection{Initial and boundary conditions}

The reservoir was initially saturated with formation water. The initial temperature and pressure of the reservoir were $150^{\circ} \mathrm{C}$ and hydrostatic pressure, respectively. For the wellhead, the initial pressure was atmospheric pressure.

For the boundary conditions, the $\mathrm{CO}_{2}$ fluid was injected at a constant flow $(8 \mathrm{~kg} / \mathrm{s})$, such that the wellbore-reservoir coupling model and the simple reservoir model were supplied with the same amount of $\mathrm{CO}_{2}$. To control the pressure variation in the reservoir, the recovery flow rate was set to $9 \mathrm{~kg} / \mathrm{s}$ in the first three years, slightly higher than the injection flow rate, and then lowered to the injection flow rate. Otherwise, if the two flow rates were the same from the very start, the reservoir will witness sharp pressure rise in the short term, for the five-point model is surrounded by zero-flow boundaries and the $\mathrm{CO}_{2}$ is much less dense than water. The operation period of the water-rock-gas system was set to 30 years. The initial and boundary conditions are detailed in Table 3.

Table 3. The initial and boundary conditions of our model

\begin{tabular}{c|c}
\hline \multicolumn{2}{c}{ Initial condition } \\
\hline Well bottom temperature & $150^{\circ} \mathrm{C}$ \\
Well bottom pressure & $36.7 \mathrm{MPa}$ \\
\hline \multicolumn{2}{c}{ Boundary condition } \\
\hline \multicolumn{2}{c}{$20^{\circ} \mathrm{C}$} \\
Injection temperature & $8 \mathrm{~kg} / \mathrm{s}$ \\
Injection mass rate & $\mathrm{yr}) / 8 \mathrm{~kg} / \mathrm{s}(4-30 \mathrm{yr})$ \\
Production mass rate & $9 \mathrm{~kg} / \mathrm{s}(1-3 \mathrm{~g}$
\end{tabular}

Both relative permeability and capillary pressure play a role in the gas-liquid two-phase displacement of the model. The two factors were simulated by the van Genuchten model for relative permeability and capillary pressure. The specific parameters of the model are shown in Table 4.

Table 4. The parameters of the van Genuchten model

\begin{tabular}{c|c}
\hline \multicolumn{2}{c}{ Relative permeability model } \\
\hline Irreducible water saturation & 0.15 \\
Irreducible gas saturation & 0.01 \\
Maximum water saturation & 1.00 \\
mvG & 0.65 \\
\hline \multicolumn{2}{c}{ Capillary pressure model } \\
\hline Irreducible water saturation & 0.03 \\
Maximum water saturation & 1.00 \\
mvG & 0.4118 \\
Alpha & $6.08 \times 10^{-5} \mathrm{~Pa}^{-1}$ \\
Maximum capillary pressure & $6.4 \times 10^{7} \mathrm{~Pa}^{2}$ \\
\hline
\end{tabular}

\subsection{Initial mineral composition}

The mineral composition and relevant reaction kinetic parameters of the reservoir are provided in Table 5

Table 5. Reaction kinetic parameters of primary and secondary minerals

\begin{tabular}{|c|c|c|c|c|c|c|c|c|c|c|}
\hline \multirow[t]{3}{*}{ Mineral } & \multirow[t]{3}{*}{ Volume fraction } & \multirow{3}{*}{$\underset{\left(\mathrm{cm}^{2} / \mathrm{g}\right)}{\mathrm{A}}$} & \multicolumn{8}{|c|}{ Parameters for kinetic rate law } \\
\hline & & & \multicolumn{2}{|c|}{ Neutral mechanism } & \multicolumn{3}{|c|}{ Acid mechanism } & \multicolumn{3}{|c|}{ Base mechanism } \\
\hline & & & $\mathrm{k}_{25}\left(\mathrm{~mol} / \mathrm{m}^{2} / \mathrm{s}\right)$ & $\mathrm{Ea}(\mathrm{kJ} / \mathrm{mol})$ & $\mathrm{k}_{25}\left(\mathrm{~mol} / \mathrm{m}^{2} / \mathrm{s}\right)$ & $\mathrm{Ea}$ & $\mathrm{n}\left(\mathrm{H}^{+}\right)$ & $\mathrm{k}_{25}\left(\mathrm{~mol} / \mathrm{m}^{2} / \mathrm{s}\right)$ & $\mathrm{Ea}$ & $\mathrm{n}\left(\mathrm{H}^{+}\right)$ \\
\hline \multicolumn{11}{|l|}{ Primary minerals } \\
\hline Quartz & 39.0 & 9.8 & $1.02 \times 10^{-14}$ & 87.7 & & & & & & \\
\hline K-feldspar & 16.0 & 9.8 & $3.89 \times 10^{-13}$ & 38 & $8.71 \times 10^{-11}$ & 51.7 & 0.5 & $6.31 \times 10^{-22}$ & 94.1 & -0.823 \\
\hline Albite & 9.5 & 9.8 & $2.75 \times 10^{-13}$ & 69.8 & $6.92 \times 10^{-11}$ & 65.0 & 0.457 & $2.51 \times 10^{-16}$ & 71.0 & -0.572 \\
\hline Anorthite & 5.0 & 9.8 & $7.59 \times 10^{-13}$ & 17.8 & $3.16 \times 10^{-4}$ & 16.6 & 1.411 & & & \\
\hline Kaolinite & 3.0 & 151.6 & $6.92 \times 10^{-14}$ & 22.2 & $4.90 \times 10^{-12}$ & 65.9 & 0.777 & $8.91 \times 10^{-18}$ & 17.9 & -0.472 \\
\hline Illite & 2.0 & 151.6 & $1.66 \times 10^{-13}$ & 35.0 & $1.05 \times 10^{-11}$ & 23.6 & 0.34 & $3.02 \times 10^{-17}$ & 58.9 & -0.4 \\
\hline Na-smectite & 2.0 & 151.6 & $1.66 \times 10^{-13}$ & 35.0 & $1.05 \times 10^{-11}$ & 23.6 & 0.34 & $3.02 \times 10^{-17}$ & 58.9 & -0.4 \\
\hline Ca-smectite & 2.0 & 151.6 & $1.66 \times 10^{-13}$ & 35.0 & $1.05 \times 10^{-11}$ & 23.6 & 0.34 & $3.02 \times 10^{-17}$ & 58.9 & -0.4 \\
\hline Chlorite & 2.0 & 9.8 & $3.02 \times 10^{-13}$ & 88.0 & $7.76 \times 10^{-12}$ & 88.0 & 0.50 & & & \\
\hline Annite & 3.0 & 9.8 & $2.82 \times 10^{-13}$ & 22.0 & $1.45 \times 10^{-10}$ & 22.0 & 0.525 & & & \\
\hline Phlogopite & 3.0 & 9.8 & $2.82 \times 10^{-13}$ & 22.0 & $1.45 \times 10^{-10}$ & 22.0 & 0.525 & & & \\
\hline Calcite & 4.5 & 9.8 & $1.55 \times 10^{-9}$ & 23.5 & $1.55 \times 10^{-6}$ & 14.4 & 1.0 & & & \\
\hline Dolomite & & 9.8 & $2.95 \times 10^{-8}$ & 52.2 & $6.46 \times 10^{-4}$ & 36.1 & 0.5 & & & \\
\hline Non-reactive & 9.0 & 9.8 & & & & & & & & \\
\hline \multicolumn{11}{|c|}{ Secondary minerals } \\
\hline Dawsonite & & 9.8 & $1.26 \times 10^{-9}$ & 62.8 & $6.46 \times 10^{-4}$ & 36.1 & 0.5 & & & \\
\hline Ankerite & & 9.8 & $1.26 \times 10^{-9}$ & 62.8 & $6.46 \times 10^{-4}$ & 36.1 & 0.5 & & & \\
\hline Siderite & & 9.8 & $1.26 \times 10^{-9}$ & 62.8 & $6.46 \times 10^{-4}$ & 36.1 & 0.5 & & & \\
\hline
\end{tabular}




\section{RESULTS ANALYSIS}

\subsection{Analysis of water and heat transfer}

Figure 2 describes the temperature evolution as the $\mathrm{CO}_{2}$ fluid was injected into the well bottom, as simulated by the wellbore-reservoir coupling model. It can be seen that the $\mathrm{CO}_{2}$ temperature increased from $20^{\circ} \mathrm{C}$ at the wellhead to nearly $80^{\circ} \mathrm{C}$ at the bottom, under the combined effect of the JouleThomson effect, the heat transfer with the surrounding rocks on the walls, and the gravitational potential energy. The temperature at the bottom of the production well was reduced by $10^{\circ} \mathrm{C}$ over the 30 years.

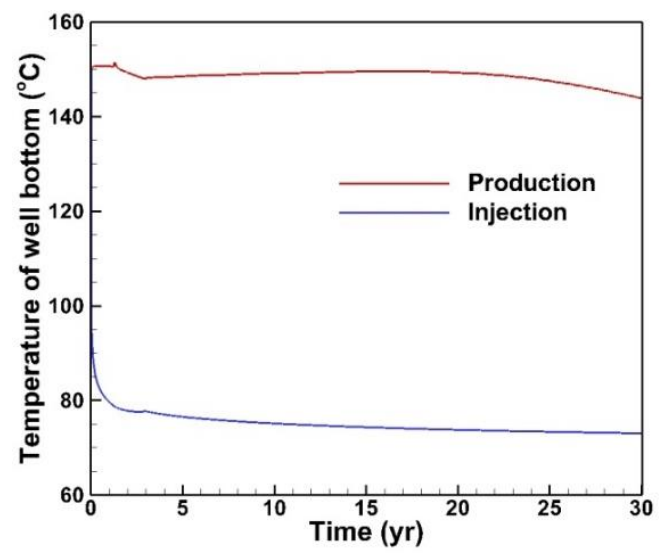

Figure 2. The time-variation in temperatures of the injected $\mathrm{CO}_{2}$ fluid and at the bottom of the production well

During the operation of the water-rock-gas system, the wellhead temperature and the gas saturation of the production well are illustrated in Figure 3. As shown in the figure, the $\mathrm{CO}_{2}$ breakthrough occurred at about 1.5 years; thus, the gas saturation of the production well soared rapidly and then remained basically stable. In the first 1.5 years, the wellhead temperature gradually increased due to the surge of hot water from the bottom. After the $\mathrm{CO}_{2}$ breakthrough, the temperature gradually declined with the rise in gas saturation, until reaching about $80^{\circ} \mathrm{C}$, under the combined effect of the JouleThomson effect and the heat transfer with the walls.

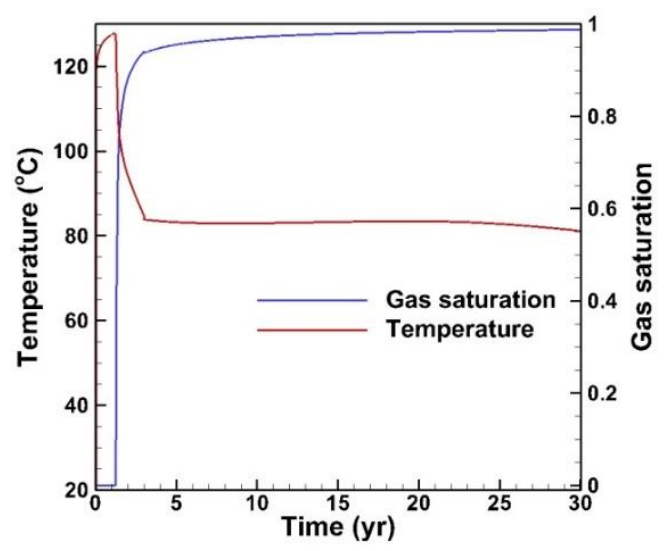

Figure 3. The time-variation of wellhead temperature and gas saturation of the production well

The left part of Figure 4 describes the time-variation in bottom pressures of the injection well and the production well. It can be inferred that the pressure of the entire region surged up with the injection of $\mathrm{CO}_{2}$ before the breakthrough, and plunged rapidly after the breakthrough. Once the recovery flow rate was reduced to the level of the injection flow rate, the pressure remained basically stable until the end of the simulation. Throughout the system operation, the injection well had a higher bottom pressure than the production well, because the fluid flowed from the former well to the latter well.

The right part of Figure 4 presents the time-variation in wellhead pressures of the injection well and the production well. The general trend of wellhead pressures was largely the same as that of bottom pressures, except that the wellhead pressure of the injection well stayed below that of the production well in the production plateau from the $3^{\text {rd }}$ to the $30^{\text {th }}$ year. This is attributable to the following facts: The bottom pressure basically equals the sum of the wellhead pressure and the cumulative pressure of gravity. Since the $\mathrm{CO}_{2}$ density varies drastically with temperature, the two wells differed greatly in the cumulative pressure of gravity, due to their huge temperature difference.
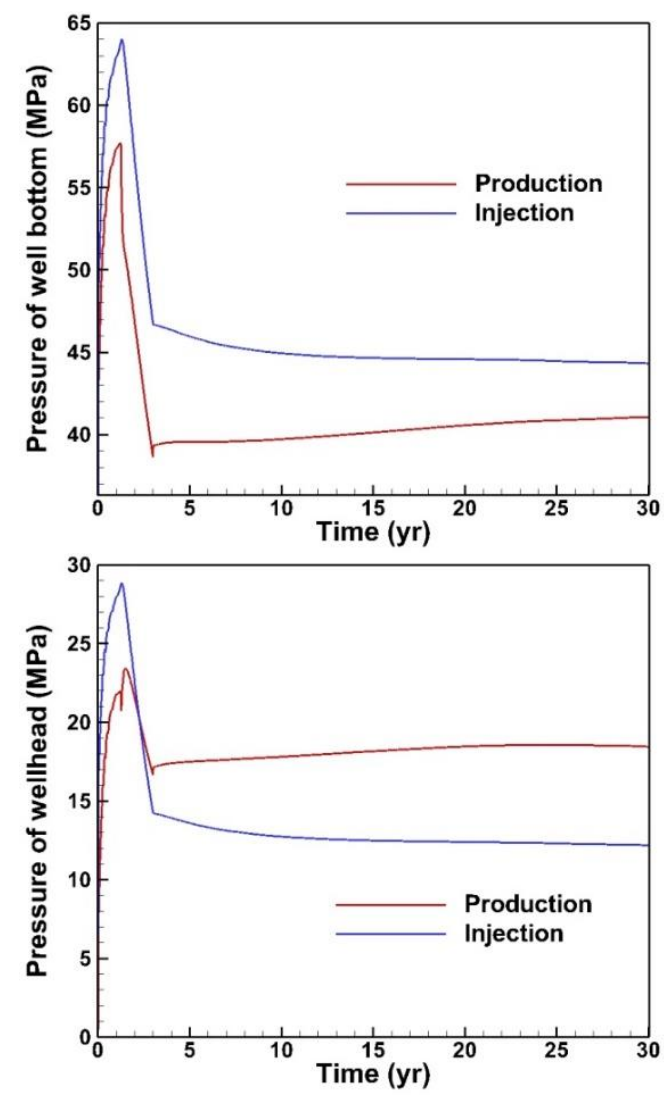

Figure 4. The time-variation in bottom pressures (left) and wellhead pressures (right) of the injection well and the production well

Figures 5 and 6 show the temperature and gas saturation of the reservoir after 30 years of system operation, respectively. There is a huge difference in temperature between the wellbore-reservoir coupling model and the simple reservoir model, owing to the series of thermodynamic processes of $\mathrm{CO}_{2}$ in the wellbore. By the wellbore-reservoir coupling model, the $\mathrm{CO}_{2}$ almost reached $80{ }^{\circ} \mathrm{C}$ at the bottom. Moreover, the wellbore-reservoir coupling model output a higher saturation than the simple reservoir model. This is because the $\mathrm{CO}_{2}$ density decreases with the growth in temperature, and the same amount of $\mathrm{CO}_{2}$ occupies a large space under a high temperature. 

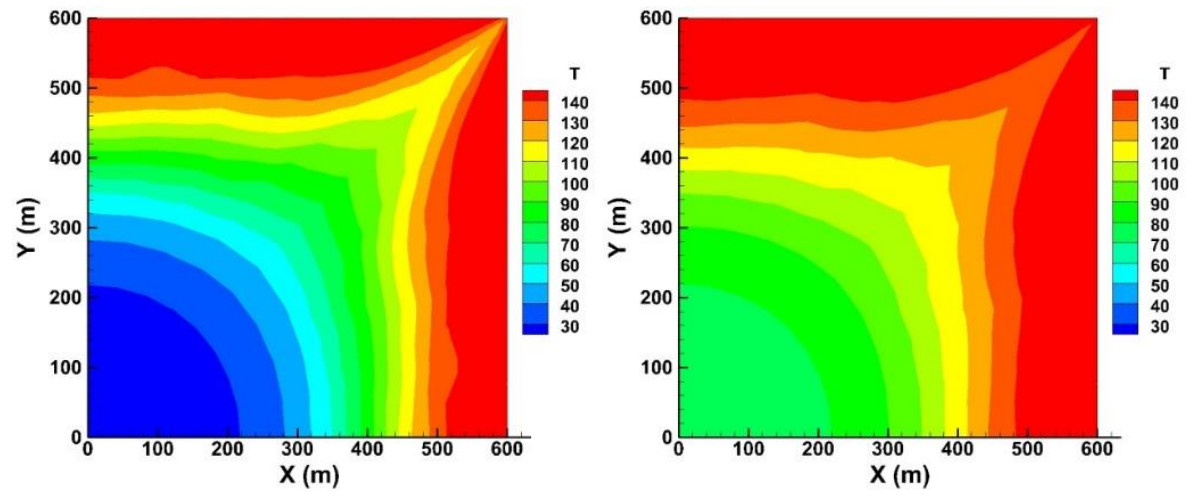

Figure 5. Distributions of reservoir temperature of the simple reservoir model (left) and the wellbore-reservoir coupling model (right)
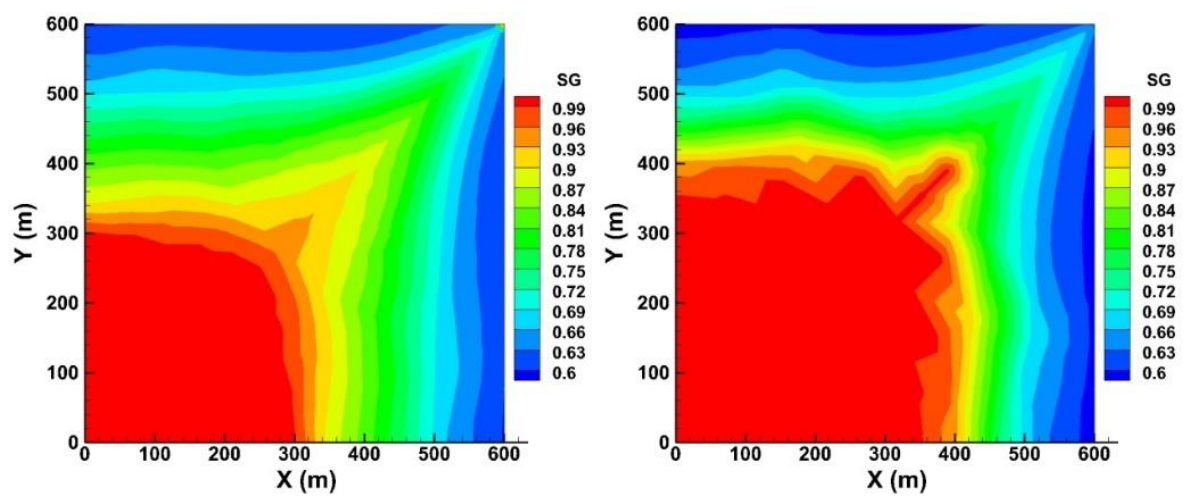

Figure 6. Distributions of $\mathrm{CO}_{2}$ saturation in the reservoir of the simple reservoir model (left) and the wellbore-reservoir coupling model (right)

\subsection{Analysis on mineral reactions}

The mineral reaction rate has a positive correlation with temperature. The temperature variation in the reservoir may induce a huge difference in geothermal reactions. After the $\mathrm{CO}_{2}$ injection, the geothermal reactions generally obey the following law: The dissolution of $\mathrm{CO}_{2}$ in water reduces the $\mathrm{pH}$, turning the solution acidic. Then, the calcite and feldspar are dissolved, while quartz, clay and some carbonates are precipitated.

Figure 7 presents the variation in the volume fractions of dawsonite, as predicted by the wellbore-reservoir coupling model and the simple reservoir model. Dawsonite is an important carbon-fixing mineral, and a key indicator of $\mathrm{CO}_{2}$ gas reservoir. A high temperature is more favorable for the formation of dawsonite. As shown in Figure 7, both models predicted a low total volume of dawsonite, but differed greatly in the magnitude of volume variation.

Ankerite is another important carbon-fixing mineral. Compared with dawsonite, ankerite can form easily under high temperature in the gas-water two-phase mixed zone near the production well. As shown in Figure 8, the wellbore-reservoir coupling model and the simple reservoir model predicted similar distributions of ankerite, with a slight difference in the gas-water interface. Moreover, the wellbore-reservoir coupling model estimated a higher temperature and more precipitation of ankerite than the other model.
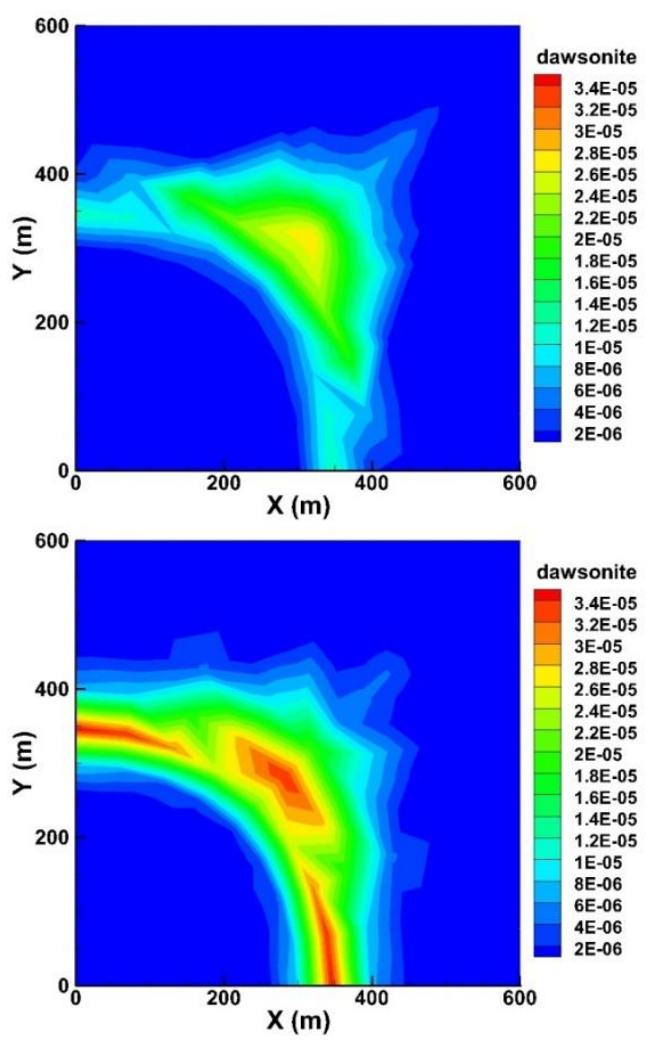

Figure 7. The variation in the volume fractions of dawsonite of the simple reservoir model (left) and the wellborereservoir coupling model (right) 

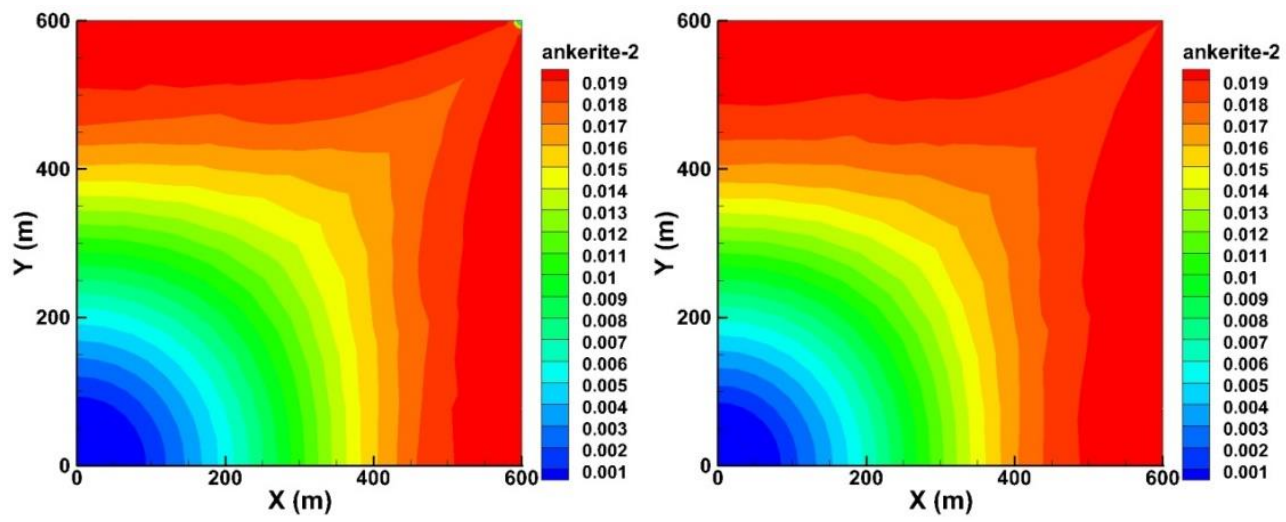

Figure 8. The variation in the volume fractions of ankerite of the simple reservoir model (left) and the wellbore-reservoir coupling model (right)

In the geochemical reactions, the dissolved species were mainly feldspar minerals like potassium feldspar (Figure 9) and anorthite (Figure 10), and the precipitated species were mainly clay minerals like illite (Figure 11), sodium montmorillonite (Figure 12) and some carbonates (Figure 13). The wellbore-reservoir coupling model output similar dissolution and precipitation situation as the simple reservoir model, except a slightly more violent dissolution and precipitation reactions near the production well. The two models predicted basically the same results in the region near the injection well, despite the huge temperature difference. In this region, the water has been displacement by $\mathrm{CO}_{2}$ or dissolved in gaseous $\mathrm{CO}_{2}$. The pure $\mathrm{CO}_{2}$ cannot react easily with the rocks.
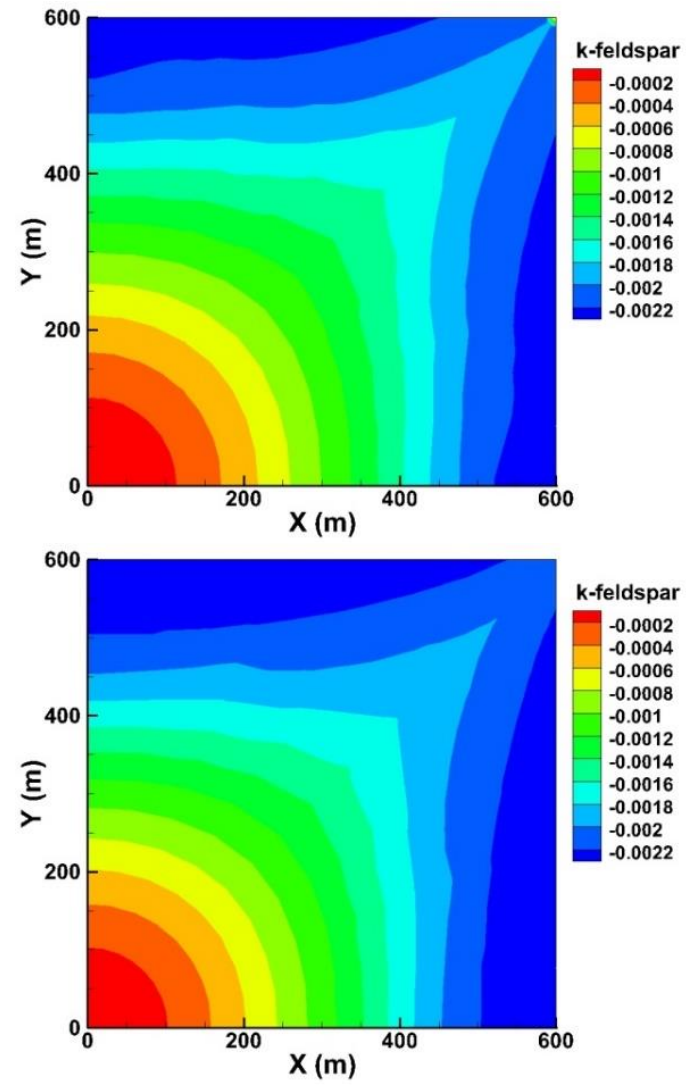

Figure 9. The variation in the volume fractions of potassium feldspar of the simple reservoir model (left) and the wellborereservoir coupling model (right)
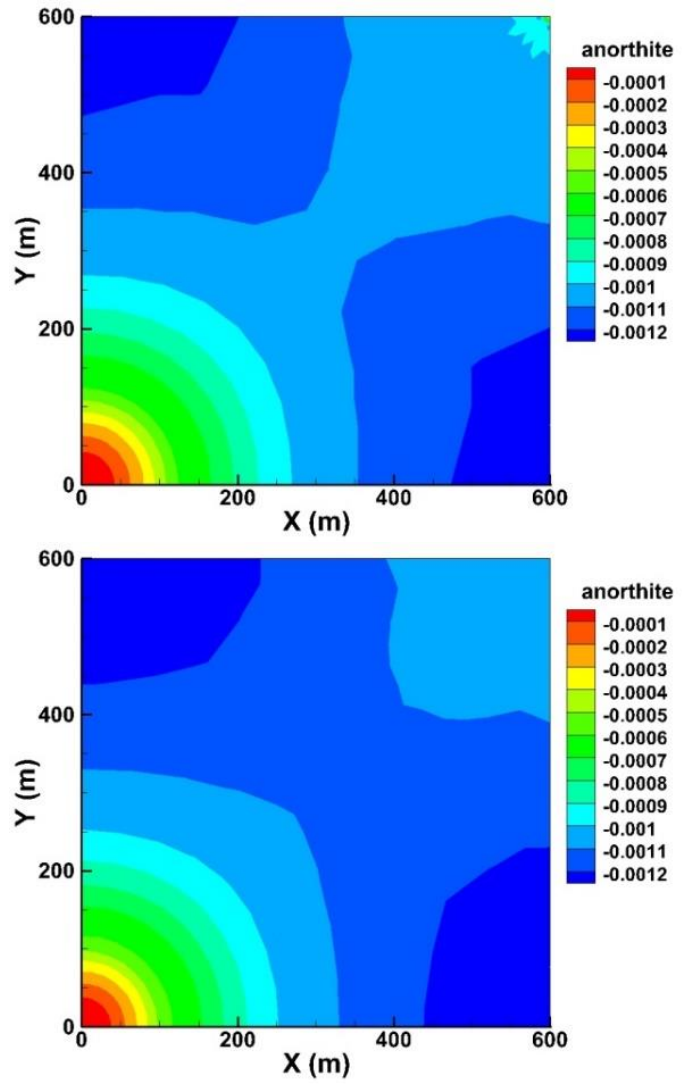

Figure 10. The variation in the volume fractions of anorthite of the simple reservoir model (left) and the wellborereservoir coupling model (right)

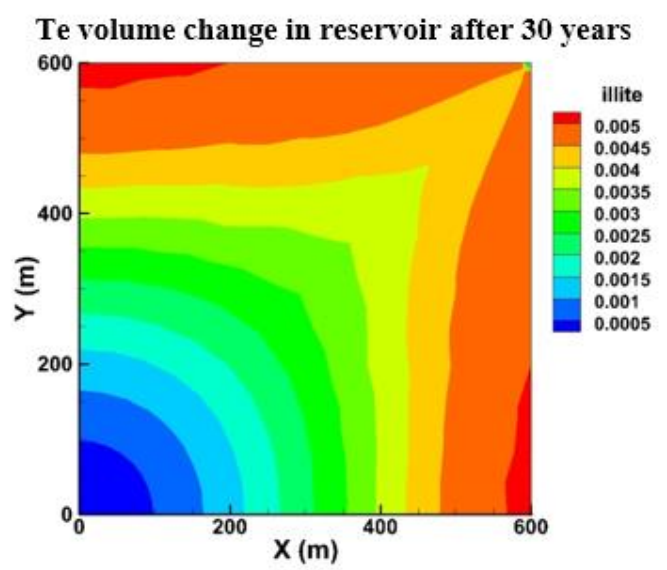




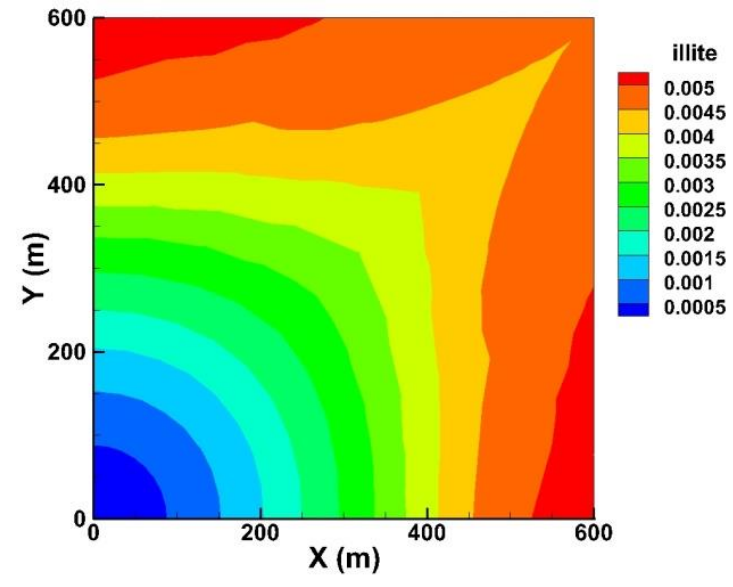

Figure 11. The variation in the volume fractions of illite of the simple reservoir model (left) and the wellbore-reservoir coupling model (right)
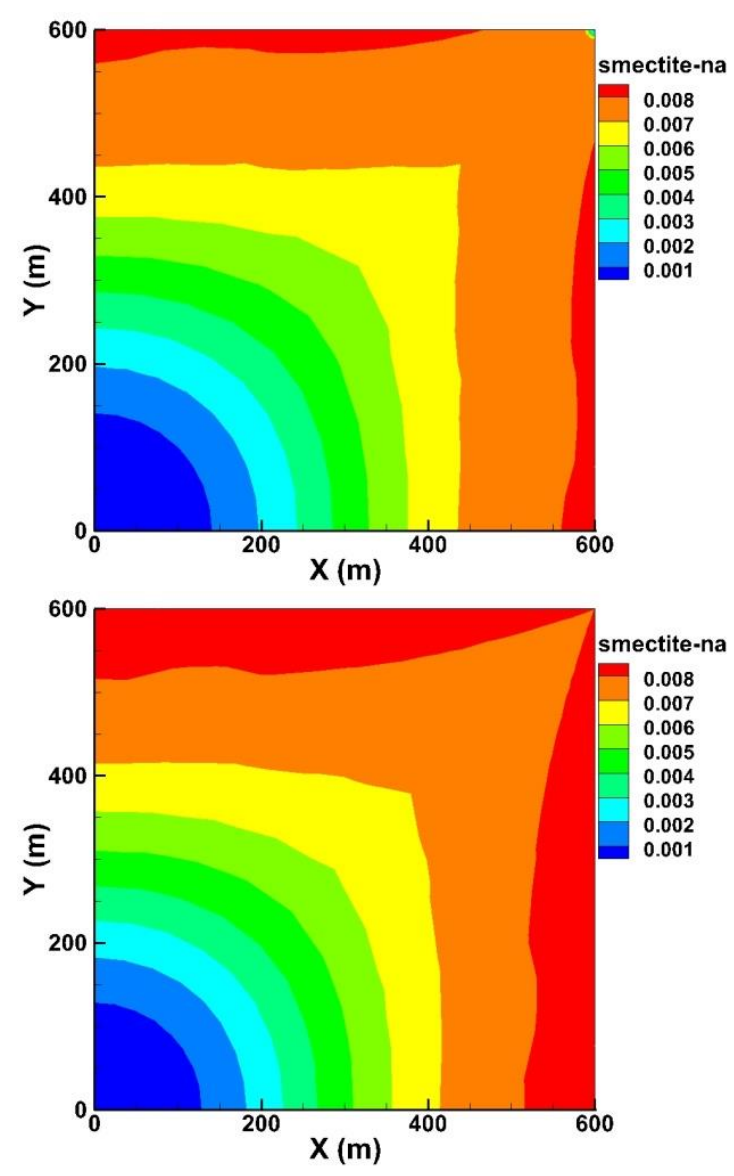

Figure 12. The variation in the volume fractions of sodium montmorillonite of the simple reservoir model (left) and the wellbore-reservoir coupling model (right)

\subsection{Analysis on CCS amount}

Figure 13 compares the CCS amounts $\left(\mathrm{kg} / \mathrm{m}^{3}\right)$ per unit volume of minerals in the reservoir of the wellbore-reservoir coupling model and the simple reservoir model. It can be seen that the wellbore-reservoir coupling model captured and stored more $\mathrm{CO}_{2}$ near the production well than the other model, thanks to the coexistence of gas and water and the relatively high temperature.
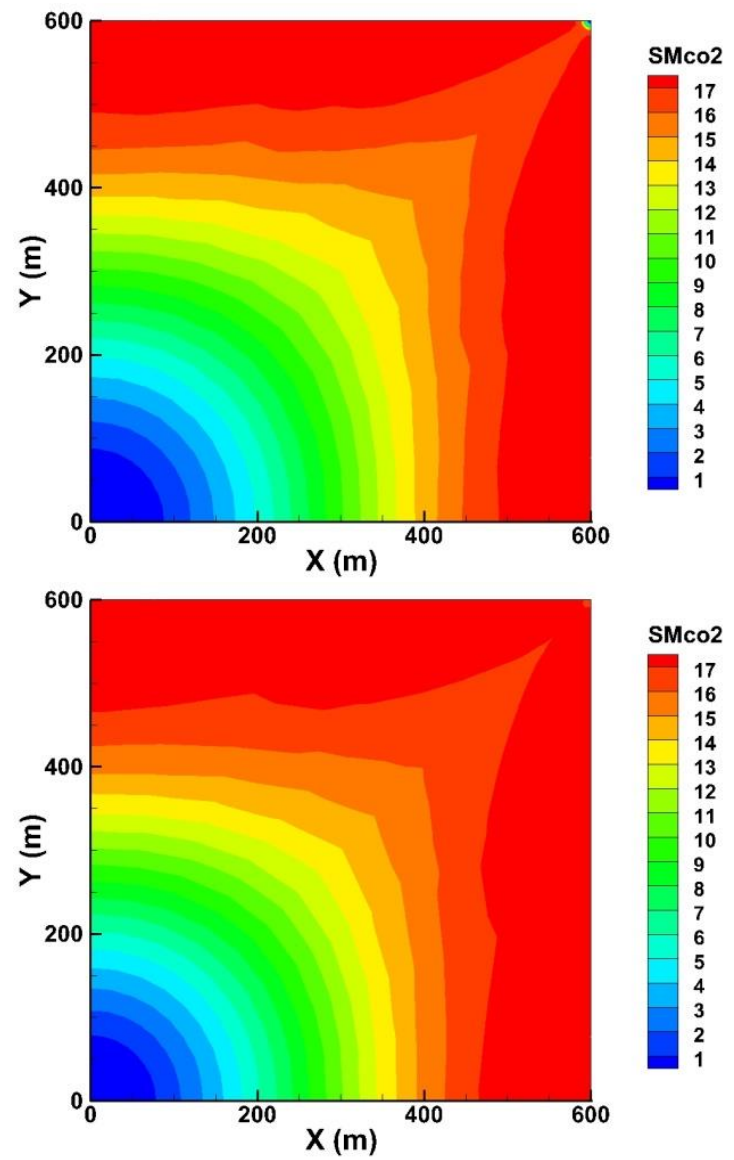

Figure 13. The CCS amounts per unit volume of minerals in the reservoir of the simple reservoir model (left) and the wellbore-reservoir coupling model (right)

As shown in Figure 14, the wellbore-reservoir coupling model predicted a slightly higher CCS amount than the other model. The possible reason is that a high temperature, a key parameter of geochemical reactions, speeds up the chemical reactions, enhancing the CCS ability.

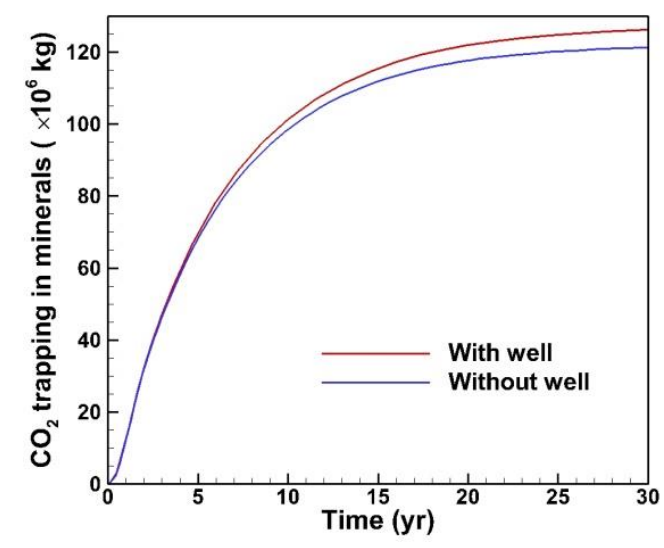

Figure 14. The time variation in the total CCS amount of minerals in the reservoir of the simple reservoir model (left) and the wellbore-reservoir coupling model (right)

\section{CONCLUSIONS}

The wellbore is indispensable for is all geological engineering operations. Without considering the wellbore, the simple reservoir simulation will incur a huge error, failing to 
predict important parameters (e.g. pressure and temperature) of injection and production accurately.

Temperature is a key parameter of the geochemical reactions involving $\mathrm{CO}_{2}$. The accurate calculation of the $\mathrm{CO}_{2}$ temperature entering the reservoir helps to quantify the intensity of water-rock-gas interaction, the mineral dissolution and precipitation and the form of CCS.

Targeting a CPG project in the Songliao Basin, this paper compares the wellbore-reservoir coupling model and the simple reservoir model in terms of water and heat transfer, mineral dissolution and precipitation, change in pore permeability, and the CCS of minerals.

The comparison shows that $\mathrm{CO}_{2}$ in the wellbore varies greatly in temperature and pressure, due to its complex thermodynamic properties and flow states; the injection well is much hotter at the bottom than at the wellhead.

The mineral reactions are generally the dissolution of feldspar and precipitation of clay and carbonates. In the region near the injection well, the two models differed slightly despite the huge temperature difference, because geothermal reactions cannot occur easily without enough water. The main difference between the two models is that: the wellborereservoir coupling model predicted slightly more violent dissolution and precipitation reactions and a greater CCS amount near the production well than the other model.

The research findings prove the necessity of the wellborereservoir coupling model, laying the basis for the simulation of $\mathrm{CO}_{2}$ geological engineering.

\section{ACKNOWLEDGMENT}

This paper is supported by National Natural Science Foundation of China (Grant No.: 51606084), Key Science and Technology Research and Development (R\&D) Project of Science and Technology Department, Jilin Province (Grant No.: 20180201078SF), Science and Technology Plan Project of Science and Technology Department, Jilin Province (Key Project of Natural Science Fund) (Grant No.: 20170101072JC) and 13th Five-Year Plan Science and Technology Project of Department of Education, Jilin Province (Grant No.: JJKH20180599KJ).

\section{REFERENCES}

[1] IPCC (2001). The Intergovernmental Panel on Climate Change, Third Assessment Report, Cambridge University Press.

[2] Han, G., Zhang, M., Bao, L. (2012). Analysis of technical approaches and development prospect of CCUS technology. Electric Power Environmental Protection, 28(4): $\quad 8-10 . \quad$ https://doi.org/10.3969/j.issn.16748069.2012.04.003

[3] Mi, J., Mi, X. (2019). Development trend analysis of carbon capture, utilization and storage technology in China. Journal of Chinese Electrical Engineering, 39(09): 2537-2544.

[4] Zhong, P., Peng, S., Jia, L., Zhamg, J. (2011) Development of carbon capture, utilization and storage (CCUS) technology in China. China Population, Resources and Environment, 21(12): 41-45.

[5] Brown, D. (2000). A hot dry rock geothermal energy concept utilizing supercritical $\mathrm{CO}_{2}$ instead of water.
Stanford University, Stanford, California, SGP-TR-165.

[6] Atrens, A.D., Gurgenci, H., Rudolph, V. (2009). $\mathrm{CO}_{2}$ thermosiphon for competitive geothermal power generation. Energy \& Fuels, 23(1): 553-557. https://doi.org/10.1021/ef800601z

[7] Randolph, J.B., Saar, M.O. (2011). Coupling carbon dioxide sequestration with geothermal energy capture in naturally permeable, porous geologic formations: Implications for $\mathrm{CO}_{2}$ sequestration. Energy Procedia, 4: 2206-2213. https://doi.org/10.1016/j.egypro.2011.02.108

[8] Luo, F., Xu, R.N., Jiang, P.X. (2014). Numerical investigation of fluid flow and heat transfer in a doublet enhanced geothermal system with $\mathrm{CO}_{2}$ as the working fluid $\left(\mathrm{CO}_{2}\right.$-EGS). Energy Procedia, 64: 307-302. https://doi.org/10.1016/j.energy.2013.10.048

[9] Xu, T., Feng, G., Hou, Z., Tian, H., Shi, Y., Lei, H. (2015). Wellbore-reservoir coupled simulation to study thermal and fluid processes in a $\mathrm{CO}_{2}$-based geothermal system: identifying favorable and unfavorable conditions in comparison with water. Environmental Earth Sciences, 73(11): 6797-6813. https://doi.org/10.1007/s12665-0154293-y

[10] Ruan, B., Xu, R., Wei, L., Ouyang, X., Luo, F., Jiang, P. (2013). Flow and thermal modeling of $\mathrm{CO}_{2}$ in injection well during geological sequestration. International Journal of Greenhouse Gas Control, 19: 271-80.

[11] Singh, A.K., Boettcher, N., Wang, W., Park, C.H., Goerke, U.J., Kolditz, O. (2011). Non-isothermal effects on two-phase flow in porous medium: $\mathrm{CO}_{2}$ disposal into a saline aquifer. Energy Procedia, 4: 3889-3895. https://doi.org/10.1016/j.egypro.2011.02.326

[12] Xu, T., Feng, G., Shi, Y. (2014). On fluid-rock chemical interaction in $\mathrm{CO}_{2}$-based geothermal systems. Journal of Geochemical Exploration, 144: 179-193. https://doi.org/10.1016/j.gexplo.2014.02.002

[13] Hangx, S.J.T., Spiers, C.P. (2009). Reaction of plagioclase feldspars with $\mathrm{CO}_{2}$ under hydrothermal conditions. Chemical Geology, 265(1-2): 88-98. https://doi.org/10.1016/j.chemgeo.2008.12.005

[14] Xu, T., Apps, J.A., Pruess, K. (2004). Numerical simulation of $\mathrm{CO}_{2}$ disposal by mineral trapping in deep aquifers. Applied Geochemistry, 19(6): 917-936. https://doi.org/10.1016/j.apgeochem.2003.11.003

[15] Xu, T., Zheng, L., Tian, H. (2011). Reactive transport modeling for $\mathrm{CO}_{2}$ geological sequestration. Journal of Petroleum Science and Engineering, 78(3-4): 765-777. https://doi.org/10.1016/j.petrol.2011.09.005

[16] Lu, M., Connell, L.D. (2014). The transient behaviour of $\mathrm{CO}_{2}$ flow with phase transition in injection wells during geological storage-Application to a case study. Journal of Petroleum Science and Engineering, 124: 7-18. https://doi.org/10.1016/j.petrol.2014.09.024

[17] Xu, T., Spycher, N., Sonnenthal, E., Zhang, G., Zheng, L., Pruess, K. (2011). TOUGHREACT Version 2.0: A simulator for subsurface reactive transport under nonisothermal multiphase flow conditions. Computers \& Geosciences, 37(6): 763-774. https://doi.org/10.1016/j.cageo.2010.10.007

[18] Pan, L., Oldenburg, C.M. (2014). T2Well-An integrated wellbore-reservoir simulator. Computers \& Geosciences, 65: 46-55. https://doi.org/10.1016/j.cageo.2013.06.005

[19] Shi, H., Stanford, U., Holmes, J., Geoquest, S., Durlofsky, L., Etc, C., Aziz, K., Diaz, L., Alkaya, B., Oddie, G. 
(2005). Drift-flux modeling of two-phase flow in wellbores. SPE Journal, 10(1): 24-33. https://doi.org/10.2118/84228-PA

[20] Pan, L., Webb, S., Oldenburg, C.M. (2011). Analytical solution for two-phase flow in a wellbore using the driftflux model. Advances in Water Resources, 34(12): 16561665. https://doi.org/10.1016/j.advwatres.2011.08.009

[21] Pan, L., Oldenburg, C.M., Wu, Y., Pruess, K. (2009).
Wellbore flow model for carbon dioxide and brine. Energy $\quad$ Procedia, 1(1): 71-78. https://doi.org/10.1016/j.egypro.2009.01.012

[22] Spycher, N., Pruess, K. (2010). A phase-partitioning model for $\mathrm{CO}_{2}$-brine mixtures at elevated temperatures and pressures: Application to $\mathrm{CO}_{2}$-enhanced geothermal systems. Transport Porous Media, 82: 173-196. https://doi.org/10.1007/s11242-009-9425-y 